\title{
Jóvenes: historia glocal de un concepto en evolución ${ }^{1}$
}

Young people: history of a concept glocal evolving

Jovem:história glocal de um conceito em evolução

\author{
Álvaro Acevedo Tarazona ${ }^{2}$ \\ Andrés David Correa Lugos ${ }^{3}$
}

Recibido: 20.06.2016 • Arbitrado:15.10.2016 • Aprobado: 01.11.2016

\section{Resumen}

Los jóvenes han sido objeto de producción y sujeto de consumo, especialmente en las últimas décadas, lo que ha desencadenado una nueva perspectiva en sus formas de asumir el mundo y manifestar su inconformismo ante diferentes eventos políticos o sociales. El presente artículo muestra la evolución del concepto de juventud desde la Antigüedad y su posterior inserción en la dinámica de la globalización actual para lo que propone un análisis de la función y el sentido de ser

\footnotetext{
${ }^{1}$ Este artículo hace parte del proyecto de investigación financiado por la Universidad Industrial de Santander denominado ¿Colombia indignada? Estudiantes y movilización por la educación superior (2011-2012). Proyecto UIS. Código: 1761. Y de la convocatoria interna de la Universidad Industrial de Santander "Eloy Valenzuela" 2015.

${ }^{2}$ Posdoctorado en Ciencias de la Educación de la Universidad Pedagógica y Tecnológica de Colombia (UPTC)-Rudecolombia; Profesor Titular de la Universidad Industrial de Santander; Bucaramanga, Colombia; tarazona20@ gmail.com; acetara@uis.edu.co.

${ }^{3}$ Historiador y Archivísta en formación de la Universidad Industrial de Santander; Miembro del Grupo de Investigación Políticas, Sociabilidades y Representaciones Histórico-Educativas de la Universidad Industrial de Santander; Bucaramanga, Colombia; andrescorrealugos@outlook.com.
} 
joven y reconoce en 1968 el punto de quiebre de una generación que, en busca de la independencia que los hiciera sentir únicos, les llevó a convertirse en autómatas de una sociedad capitalista que los ha subyugado ante la paranoia de la tecnología y el ciberconsumo.

Palabras Clave: juventud, globalización, tecnología, consumo, 1968, globalidad

\section{Abstract}

Young people have been the subject of production and consumption, especially in recent decades, which has triggered a new perspective on their ways to take on the world and express their nonconformity to different political or social events. This article shows the evolution of the concept of youth from antiquity and subsequent insertion into the dynamics of the current globalization for what proposes an analysis of the role and the sense of being young and recognized in 1968 the turning point of a generation in search of independence that made them feel unique he led them to become automatons of a capitalist society that has subjugated to the paranoia of technology and ciberconsumer.

Keywords: youth, globalization, technology, consumer, globality

\section{Resumo}

Os jovenstêm sido objecto de produção e consumo, especialmente nas últimas décadas, o que provocouuma nova perspectiva sobre as suasmaneiras de tomar sobre o mundo e expressar a suainconformidadecom diferentes eventos políticos ousociais. Este artigo mostra a evolução do conceito de juventude desde a antiguidade e subsequenteinserção na dinâmica da globalizaçãoatual para o que se propõeumaanálise do papel e sentido de ser jovem e reconhecidoem 1968 o ponto de viragem de umageraçãoem busca de independência que os fez sentir única levou-os a tornar-se autômatos de umasociedade capitalista que temsubjugado à paranóia da tecnologia e ciberconsumo.

Palavras-chave: juventude, globalização, tecnologia, consumo, a globalidade 


\section{Introducción}

iAl fondo de lo desconocido para encontrar lo nuevo!

(Baudelaire: 2009)

La sociedad contemporánea o sociedad globalizada está inscrita en una dinámica de producción y consumo acelerado que incrementa el desarrollo tecnológico a niveles exponenciales (Bauman, 2013). El éxito de este modelo que permea las sociedades desde el plano económico y político hasta el científico y cultural, radica en el mejoramiento continuo, sistemático e intensivo de todas las líneas de producción y servicios orientadas a la simplificación, el confort y el placer (Lipovetsky y Serroy, 2015). Más allá de generar cuantiosas ganancias -que lo hace-, el consumo fabrica experiencias por medio de mercancías que crean la ilusión de un momento que vale la pena de ser recordado, todo un triunfo del marketing.

La producción en serie y acelerada en procura de un ideal de innovación lleva a una obsolescencia incesante de máquinas, equipos y tecnologías, dejando arcaicas mercancías y productos. El problema se agudiza cuando la dinámica innovación-obsolescencia trasciende a categorías sociales y hace ver a los seres humanos como entes arcaicos que no tienen competencias ni cumplen con los requisitos básicos para sobrevivir en un mundo globalizado (McLuhan, 1965). Desde luego, el malestar no se hace esperar y es cuando se incrementan las protestas y movilizaciones sociales en todo el planeta en torno a un modelo que también hace a los seres humanos obsolescentes y debilita la percepción de sí mismos hasta el punto de concebirlos como una máquina o un gadget útil para la producción de otros gadgets o máquinas. Esta es la paradoja de la producción: "soy producido para producir".

En este escrito es importante preguntarse por una arqueología de la innovación y la movilización social desde la reciente era de la globalización. En la búsqueda aparecen imbricadas nociones que cambian radicalmente el desenvolvimiento de la sociedad. No es un secreto que 
el inicio de la era globalizada, desatada desde 1968, coincide con la re-conceptualización de una categoría como juventud (Wallerstein, 2003, p. 5). ¿Es entonces la liberación de la juventud un sentimiento contracultural o efecto de una semantización social que tiene por objetivo preparar un target poblacional para un acontecer en el que estándares de calidad, eficiencia y eficacia modulan la globalización? Si los conceptos son el resultado de una heurística permanente entre la teoría y la contextualización y multiplicidad de cada contemporaneidad, esta reconfiguración implica preguntarse por la noción de juventud a partir de los acontecimientos y tendencias que surgen y retan a la teoría social.

Los quiebres generacionales resultan de acontecimientos que son catalizadores de nuevas formas de interpretación del mundo (Restrepo, 2002). En esta investigación el concepto de joven responde a una reinterpretación del mundo, una nueva forma de solucionar los problemas; una perspectiva incluso utópica pero, aun así, encantadora y un síntoma paradójicamente innovador, herencia de una primera modernidad en la cual todo lo nuevo es sinónimo de progreso confrontándose ahora con un mundo glocal (Waters, 1995).

Bajo una perspectiva teórica social es importante analizar cómo los conceptos mutan frente a problemáticas que afectan la percepción del mundo, entre ellas, los miedos y las crisis económicas, e incluso por las nuevas tendencias de la cultura difundidas por los mass-media que son estandarizadas y enviadas a cada individuo. Es por esta razón que un estudio de las sociedades globalizadas va de la mano con el análisis de los distintos medios de comunicación que a partir del año 1968 dan un giro hacia la construcción de una nueva realidad de acontecimientos del mundo y la fabricación de otras realidades (virtuales) (Baudrillard, 2007).

\section{Juventud como concepto}

Hablar de "juventud" es hablar de lo nuevo. Para los griegos la traducción de joven es véos (néos) (Diccionario Vox, 1967, p. 420), una traducción adjetivada de lo nuevo, lo fresco; mientras que juventud 
veoגaía (neo-laía) es una apócope cuya traducción es "gente joven" (Diccionario Vox, 1967, p. 420). Esta perspectiva de los griegos al reconocer a los jóvenes como seres del porvenir y la esperanza es recogida por Aristóteles en su obra Retórica, en la cual realiza una radiografía social de los jóvenes:

Losjóvenes son propensos a deseary a hacer lo que desean. En cuanto alos deseos del cuerpo son especialmenteinclinados a los sexuales eincapaces de dominarlos, aunque también son inconstantes y dados a aburrirse de sus deseos; desean vehementemente pero se les pasa rápidamente [...] Son temperamentales, vehementes e inclinados a la ira, y se dejan dominar por sus impulsos, pues por su pundonor no soportan sentirse menospreciados, sino que se irritan si creen que sufren un trato injusto. Son deseosos de prestigio, pero lo son más de ganar, pues la juventud desea ardientemente la superioridad. En cambio ambas cosas son más importantes que el deseo de dinero...Porque no han experimentado aún lo que significa su falta [...] No tienen mal natural, sino bueno, porque aún no han conocido muchas perversidades (Aristóteles, 1990, p. 377).

Los jóvenes tienen una perspectiva distinta de los tiempos sociales. Su poco interés por el pasado, pero su desvelo por un futuro incierto y a la vez prometedor, permite que crean en el cambio. Esta característica establece un plus con referencia a cualquier otro grupo poblacional, aunque también esta misma característica sea considerada una de sus principales desventajas, pues pueden ser engañados y aprovechados por poderes políticos con el fin de desplegar y ensanchar sus dominios de poder.

Son confiados porque aún no les han engañado muchas veces, y esperanzados porque tienen un calor natural, semejante al que sienten los borrachos, además porque aún no les han engañado muchas veces. La mayor parte de su vida está llena de esperanza, porque la esperanza se refiere al porvenir, y el recuerdo, al pasado, y para los jóvenes el futuro es largo, y el pasado corto [...]También son engañadizos, por lo dicho, porque se esperanzan con facilidad, y más valerosos, porque son impulsivos y llenos de esperanza: lo primero les quita el miedo, lo segundo les da ánimos [...] Son vergonzosos [...] y magnánimos, pues aún no se han visto humillados por la vida [...] Prefieren realizar 
acciones hermosas mejor que provechosas, pues viven más de acuerdo a su modo de ser que con el cálculo [...] Son más amigos de sus amigos y de sus compañeros que los de las demás edades porque disfrutan de vivir en compañía y aún no eligen nada de acuerdo con el provecho, y en consecuencia, tampoco a los amigos (Aristóteles, 1990, p. 379).

La naturaleza de los jóvenes se caracteriza por ser valerosa y compleja; su ímpetu los hace creer que pueden dominar todo, son los años los que ofrecen prudencia y es el conocimiento el que vuelve humilde a los hombres, haciendo que vean desde lo particular. Para los jóvenes el mundo puede ser una broma -y una broma fatal como en el argumento de la novela La broma (Kundera, 1967)-, tal vez por esa razón a veces no son plenamente conscientes de la gravedad de sus acciones y de cómo estas pueden cambiar el mundo y hacer temblar regímenes.

Todos sus errores son por exceso e impetuosidad: aman en exceso, odian en exceso[...] Creen saberlo todo y están absolutamente seguros [...] Cometen agravios por injuriar, no por hacer daño. Son compasivos, porque suponen a todo el mundo noble y mejor de lo que es, pues miden al prójimo por el rasero de su propia inocencia [...] Son propensos a reír y por ello también bromistas, pues la broma es una insolencia atemperada por la buena educación. Así es, pues, el modo de ser de los jóvenes (Aristóteles, 1990, p. 380).

Desde un punto de vista tautológico, los jóvenes son jóvenes porque lo son. Los romanos, por su parte, llevan la condición filosófica de ser joven a una forma política con deberes sociopolíticos para cada etapa. La juventud se traduce como aduviare, un concepto que en latín designa la acción de ayudar, apoyar o sostener a alguien, y del que se deriva el vocablo iuvenis, que en español se traduce como joven (Diccionario Vox, 2011, p. 269). El iuvenis (ser joven) oscila entre los 30 y 45 años y su misión es ayudar a la sociedad. La etapa anterior es conocida como adulescens (de 18 a 29 años) y su traducción es "el que le falta algo o todavía está creciendo", del verbo adolesco (crecer, desarrollarse) (Diccionario Vox, 2011, p. 269), convirtiendo a los aduslescens en seres en construcción sin mayor responsabilidad que actuar para sí mismos. 
Posteriores categorizaciones de etapas biológicas asemejan al ser humano con procesos de desarrollo de otros organismos vivos. Por siglos tal configuración es aceptada y revalidada por la ciencia positivista que reconoce las etapas de cambio del ser humano como sinónimos de progreso (Habermas, 1989, p. 22). Esta noción se mantiene, toma fuerza y se enriquece en la modernidad: joven es algo inacabado e influenciable que no tiene espacio en las decisiones importantes como la construcción de los Estados nacionales. Este nuevo significado va convirtiendo al joven -un grupo poblacional- en espectador de un show de un mundo orientado por personas que no son jóvenes y que no tienen el menor interés de un bienestar conjunto pero sí en el lucro y la obtención de grandes capitales.

El ideal de progreso mecanicista del siglo XIX, llevado hasta sus últimas consecuencias (el progreso es indefinido y siempre en ascenso hacia mejor), le arrebata al joven toda ilusión utópica de un porvenir forjado autónoma y libremente. Geoffre y Barraclough propone que cualquier historia contemporánea parte de una historia de la tecnología y sobre todo de la comunicación, pues la tecnología es la que cambia la percepción de la sociedad y con ella confluyen múltiples realidades en un espacio sin dimensiones específicas (Barraclough, 1964, p. 52). El drama inicia cuando la tecnología existente y el primer influjo de mundialización se usa en 1914 para un fin específico: destruir. La Gran Guerra consume la vida de millones de jóvenes en tierras desconocidas que luchan por conflictos que no entienden (Archive.org, 2008). El lento y largo siglo XIX es interrumpido por un fulgurante, armamentista y corto siglo XX en el continente europeo. La mayoría de los nacidos a finales del siglo XIX no llegan a la mitad del XX, lo que se traduce en una crisis poblacional y social en la destruida Europa (Baker, 1996). Colombia no tiene una participación directa en los dos conflictos mundiales, pero en su interior estalla un conflicto interno; jóvenes son arrastrados por la violencia bipartidista que se traduce en matar o morir por una adscripción partidaria liberal o conservadora; el juego político y de la guerra se extiende hasta los años sesenta con los últimos reductos de las guerrillas liberales, el bandolerismo y el origen de guerrillas de tendencia marxista-leninista 
(Acevedo Tarazona, 2016, p. 31). Arrojo, crueldad y miedo configuran un panorama de guerra para aquellos jóvenes absorbidos por el conflicto y el mutismo absoluto o la descalificación por parte del Estado.

Los padres son los que callan pero los hijos son los que gritan. La generación de la posguerra hace una ruptura radical con el accionar social y las formas de movilización de sus padres, llevando a necesitar de una re-interpretación social que pueda analizar los problemas contemporáneos y las aparentes soluciones que se gestaban desde la calle, en especial en los sectores populares (Carassai, 2013, p. 84). A la re-conceptualización se suma una nueva forma de cotidianidad y una economía que genera ganancias a mediano y largo plazo. La máquina humeante y grasosa del capitalismo industrial deja de ser atractiva y el planeta parece estar quedando pequeño ante los procesos innovadores de la producción. La solución es simple: capitalizar el futuro y vender nuevas necesidades que afiancen en el consumidor satisfacción y un grado de distinción al usarlo.

Los jóvenes dejan de ser utilizados como una fuerza de destrucción y posicionamiento militar fieles a un Estado-nación. Ahora son los jóvenes los que van a incrementar la producción y consumo en la sociedad (Muñoz, 2005). Para lograrlo se hacen concesiones, entre las que se destaca ser parte activa de decisiones políticas, económicas y culturales antes reservadas a rancios capitales oligárquicos. El mundo es muy peligroso como para pensar en grandes guerras; el avance tecnológico implementa el uso de bombas termonucleares que pueden destruir el planeta como se conoce en segundos. De la catástrofe nuclear solo quedará un planeta tóxico y reducido a escombros habitado por cucarachas y a especies con exoesqueletos. Pero nadie quiere eso, lo que se quiere es aprovechar al máximo los recursos que quedan, capitalizar en el mercado especulativo el futuro de países completos y crear tanta riqueza como jamás se ha generado en toda la historia de la humanidad en menos del 1\% de la población (BBC Economy, 2012).

En Colombia la generación contemporánea a los hijos de la posguerra vive una modernización tardía con el programa de gobierno del 
General Rojas Pinilla propiciando un espacio para el desarrollo tecnócrata con proyectos revolucionarios como la televisión (1954); la automatización y afianzamiento de la telefonía; y la construcción de obras de alto impacto en el transporte como la modernización de puertos marítimos, la creación de aeropuertos en las principales ciudades y la consolidación de la energía eléctrica en el país (Ramirez, 2003). Los avances en la mejora tecnológica del país se reflejan en la coalición política entre conservadores y liberales (Frente Nacional) como una estrategia política y moderna al ejercicio del poder; en teoría se busca reconciliar capitales políticos y económicos de distinta militancia en un clima de poder consensuado y controlado (Acevedo Tarazona, 2016, pág. 25). El crecimiento de las ciudades y el posicionamiento de una nueva forma de vida urbana proyectan a los jóvenes a nuevos espacios de confrontación, no solo la academia universitaria era proclive a generar estos ambientes. El floreciente intercambio cultural con la literatura, la música y expresiones artísticas demuestran que hay más que la salida violenta a la inconformidad.

Estos jóvenes ávidos consumidores de espacios de debate y crítica social se dan cuenta muy temprano que no existe un cambio, y sin cambio no hay oportunidad y sin oportunidad no hay espacio para la utopía (Marcuse, 1968, p. 8). Por ello algunos optan por la lucha amada y otros por una visión nihilista de la realidad colombiana. Aparece entonces el nadaísmo como una tendencia contracultural. El nadaísmo no solo representa un hastío generacional sino la apertura de concepciones provincianas a un nuevo horizonte de diálogos universales (Acevedo y Restrepo, 2009). Ideas vanguardistas y revolucionarias de la filosofía de Sartre o de Camus de un hombre que se levanta contra Dios y los amos impacta en el planeta entero (Camus, 1953, p. 18), más todavía en una población como Colombia distinguida por su hermetismo cultural (Guerrero, 2008). Para Camus ser rebelde es una forma de interpretación del mundo que irradia en la relación con la sociedad; es necesaria entonces una rebelión metafísica que supere los cánones caballerescos que dictaminan normas de comportamiento y moralidad y que se difunden como resultado del castigo divino; solo cuando se 
supera esta primera etapa es cuando una sociedad piensa en el reacomodamiento contemporáneo por medio de los movimientos y luchas sociales que buscan una emancipación del hombre y su condición de estar sujeto a poderes e instituciones (Camus, 1953, p. 228).

La reflexión de un joven en París junto a uno en Medellín o Bogotá se hacen similares, existe por primera vez un acercamiento glocal entre el cosmopolitismo de las metrópolis y las denominadas periferias. El nadaísmo es un ejemplo del acercamiento del mundo a las localidades, por algo es un movimiento que inicia en la provincia colombiana confrontando no solo el sentimiento y el contra-discurso planetario de los poderes hegemónicos sino el centralismo nacional, es una mixtura propositiva entre la estética del arte y la política (Acevedo y Restrepo, 2012). El sentido de la vida para los jóvenes nadaístas recae en una actitud de vacío absoluto, pero logran cuestionar la historia oficial y las representaciones de la tradición en la sociedad colombiana y sus oscuros capítulos de sectarismos. Los nadaístas crean un lenguaje poético que impregna la imagen y el paisaje local. En los escritos de los nadaístas se encuentra una riqueza simbólica que fundamenta la relación entre una realidad dantesca y una imaginación recursiva, lo cual implica un redescubrimiento de la realidad latinoamericana con base en el diálogo directo con la cultura universal pero sin dejar el infantilismo que lo caracteriza (Acevedo y Restrepo, 2009, p. 62-78). Todo esto con un único objetivo: obtener la libertad, no como un sentimiento sino con un compromiso existencial.

¿Por qué la tendencia de los jóvenes a querer deconstruir la sociedad? La reconstruida Europa con dineros prestados por Estados Unidos del Plan Marshall evidencia un mundo en proceso de estabilización. En Latinoamérica la política y el retraso tecnológico imposibilitan la implementación de un aparato gubernamental con reglas y acciones claras sobre la participación, la inclusión y la democracia. Para entender las razones del surgimiento de jóvenes rebeldes hay que leer el malestar de jóvenes de todo el mundo. Jean Dubuffet describe el sentimiento anarquista y revolucionario de jóvenes franceses en vísperas 
del mayo del 68: "la policía está dentro de nuestra cabeza [...] del Estado no conozco sino un rostro: el de la policía, y no puedo imaginarme el ministerio de la cultura sino como la policía de la cultura" (Dubuffet, 1986, p. 66). Es un momento clave en el panorama mundial, los jóvenes quieren cambiar de una vez por toda la tradición institucionalista y cerrada que no permite acceder o por lo menos plantear la utopía de la libertad y la igualdad. Eric Hobsbawm delimita a la juventud como un sujeto histórico autónomo que lleva a cabo la "revolución cultural planetaria” y que redefine las relaciones entre las generaciones, las costumbres y, sobre todo, el consumo (Hobsbawm, 1997, p. 363).

La juventud se levanta en contra de toda noción biológico-social que la limita y la hace ver como incompleta o que adolece de conocimiento. Ser joven no significa ser menor de edad. La lucha entre una juventud preparada, informada y con mayor acceso a la educación promueve en los años sesenta reinterpretaciones sobre la naturaleza biológica: "la juventud y la vejez no están dadas, sino que se construyen socialmente en la lucha entre jóvenes y viejos" (Bourdieu, 2002, p. 164). Los alcances de la juventud de los años sesenta son bien conocidos y hacen eco en las remembranzas de antiguas luchas y codifican los mitos de las actuales. Hoy la publicidad para el consumo, incluso, ha desplazado al mito: "dime qué consumes y te diré quién eres". Una publicidad consumista que vende el bienestar, la belleza, el confort, la juventud, pero que no todos pueden comprar.

\section{Juventud y globalidad}

En la actualidad hay una mutación en la concepción de juventud.Este cambio tiene que ver con una globalización guiada por el economicismo y la tecnología que la conduce a una paradoja: por un lado, una conciencia de globalidad en una etapa de consumo nunca antes vista; por otro, la necesidad consciente de una ética planetaria que evite la depredación de lo virtual (Ulrich, 2002). Esta paradoja se complejiza hoy más por su desenvolvimiento en la arena infinita de lo virtual. Es común creer que lo virtual es todo aquello que se opone a lo real. Lo virtual posee una realidad plena: es real sin ser actual, ideal sin ser abstracto y simbólico sin ser ficticio" (Deleuze, 2002, p. 314). Se cree que lo real apela al objeto 
por lo que es en cuanto que es, pero el objeto tiene una de sus partes en lo virtual, entonces lo virtual no es algo irreal o inventado sino la otra perspectiva que unida complementa lo real. La fuerza de lo virtual es igual de fuerte a lo real en la era de los medios globalizados y deja de ser considerado un complemento para ser una forma de estar en el mundo.

Lo virtual modifica los parámetros de aceptación en la población; funciona como un escape a los vestigios éticos y morales y a la nueva conciencia planetaria. Se habla del fin del metarrelato y de la construcción de imaginarios basados en una utopía nacionalista pero Rocky (1976) es un éxito en las salas de cine; la guerra de Vietnam es condenada en el mundo entero pero Rambo lidera las taquillas y se convierte en un clásico cinematográfico. Los medios que se sobreponen a la barrera del espacio-tiempo y conducen a la instantaneidad de la información y, a la vez, al dominio de un hipertiempo perceptible solo bajo la óptica del espectador, trastornan las realidades y con ellas la percepción histórica del acontecimiento (Zizek, 2014).

La diferencia de la juventud de lo virtual con la de los años sesenta radica en su posicionamiento en medio de una información binaria que parte de una línea de tiempo "oficial” o matriz de información, pero una vez en movimiento en la red se crean múltiples ramificaciones alternas que se desvían y nunca más se conectan con la línea de tiempo "oficial" o matriz. En este caso, el receptor de información es de inmediato un emisor de información. Por lo contrario, las juventudes de los años sesenta funcionan como una pantalla-receptora: una cantidad finita de información cerrada llega a jóvenes receptores para después ser redistribuida no por la misma red de información que es recibida (McLuhan, 1969, p. 117). Mientras en el primer caso la información es interactiva entre emisor y receptor, en el segundo caso la información es pasiva entre emisor y receptor. En el año 1968 se desatan las fuerzas de un macro-acontecimiento con efectos hasta la actualidad. Lo que nadie puede entrever en ese momento son los cambios acelerados que a partir de entonces se suceden uno tras otro en la revolución de la informática y sus efectos en la sociedad planetaria. 
La juventud del siglo XXI se enfrenta a una infinidad de información procedente de la Internet. Los jóvenes reciben información pero a su vez recrean información haciendo que el ciclo sea infinito y activo. La globalización es posible cuando las realidades virtuales se encuentran, y este encuentro cambia de manera estructural la sociedad, pero también cambia a los actores sociales en un plano personal haciéndoles creer que son parte de un mismo planeta y que cualquier evento que afecte a un individuo termina afectando a todos. Esto es lo que se conoce como una dependencia glocal.

La glocalización se enfoca en el actor social, ya sea un individuo, un grupo o una comunidad. Esta adquiere todo su significado cuando se está en disposición de pensar globalmente y de actuar localmente. Implica, además, una adaptación a las peculiaridades de múltiples entornos. Se considera también como la mixtura de elementos locales, particulares y mundializados. Supone, por último, un mundo donde hay una progresiva eliminación de fronteras económicas, políticas y sociales (Robertson, 1992, p. 92).Con la posguerra se produce un cambio abrupto en la cronología del tiempo. Asimismo, las nuevas economías de mercado impactan de manera directa en los jóvenes, los límites geográficos se superan y la conciencia contracultural de los jóvenes en el planeta es tenida en cuenta. La autopercepción del papel que juega cada actor social en los acontecimientos planetarios es el punto de inflexión fundamental desde el cual se estudia esta contemporaneidad. Para ello se recurre a un panorama teórico amplio que concibe procesos sociales más profundos y reflexiona más allá de los límites de lo local y lo regional.

¿Es lo mismo globalidad y globalización? La globalización es uno de los conceptos que tiene más derivaciones en su corta duración. En menos de cincuenta años la globalización pasa de ser un modelo de liberalización de mercados a una reorganización geopolítica del mundo que tiende a suprimir el modelo de Estado-nación, a dar nuevas formas al consumo y a crear una sobre-posición de realidades (Fazio, 2011, p. 90). La inestabilidad conceptual de la globalización la convierte en un 
acontecer complejo pero a la vez atrayente de investigar. En esta permanente re-semantización de la globalización es imprescindible contextualizar explicativamente el cambio del concepto. La globalidad es un estado en el que se encuentra la sociedad globalizada; no hay ningún país ni grupo que viva al margen de los demás. Es decir, las distintas formas económicas, culturales y políticas no cesan de entremezclarse. La sociedad mundial es la totalidad de las relaciones sociales que no están integradas ni determinadas por la política del Estado-nación. La globalidad constituye una forma de ubicarse en el mundo e implica una posición frente a las lógicas de las globalizaciones ecológica, cultural, económica y social, y las que, a su vez, no son entendibles en sí mismas sino en su mutua interdependencia. La globalidad está presente en "el ensanchamiento del campo geográfico y en la creciente densidad del intercambio internacional, así como en el carácter global de la red de mercados financieros y del poder cada vez mayor de las multinacionales; en la revolución permanente en el terreno de la información y las tecnologías de la comunicación; en la exigencia de respetar no solo derechos humanos sino también culturales; en las corrientes icónicas de las industrias globales de la cultura; en el problema de la pobreza global; en daños y atentados ecológicos globales; en los conflictos políticos y culturales en un lugar concreto" (Beck, 2008, p. 35).

El concepto de globalidad es un proceso que crea vínculos y espacios trasnacionales y revaloriza culturas, rompe la unidad del Estado-nación y establece relaciones nuevas entre unidades, actores sociales, identidades, espacios y situaciones en procesos trasnacionales.La globalidad es constatable en los jóvenes que se preocupan y están atentos ante cualquier acontecimiento planetario: desde pruebas nucleares en los Atolones del Pacífico (1952), la crisis de los misiles en Cuba (1962), la matanza de estudiantes en Tlatelolco (1968) y las revueltas estudiantiles en Francia (1968), hasta la catástrofe nuclear en Chernóbil (1986), las denominadas primaveras revolucionarias en el Norte de África y Medio Oriente y la lucha por la educación en Suramérica (2011). Los acontecimientos se posicionan en un hiperespacio virtual en el que cualquier medio de información tecnológico -desde la televisión hasta 
la Internet- cambia de manera abrupta la forma de apreciar los acontecimientos y modifica a la impresionable y osada juventud.

Para ser joven es necesario ser globalizado. La contracultura da sentido a la juventud y a la globalización. Es impensable un cambio político o económico cuando los titanes ideológicos -capitalismo y comunismo- entran en un estado de simbiosis. Solo una vertiente contracultural, efecto de dicha simbiosis, empieza poco a poco a corroer los cimientos estructurales de los colosales y hasta entonces imbatibles sistemas (Marcuse, 1973, p. 140). De repente el cambio se da, es tan rápido que no es tomado en serio. La estética del consumo se extiende a nuevas colectividades que se niegan a ser parte de una masa. El desarraigo cultural de los más jóvenes da pie a sentimientos parias. El revolucionario busca la utopía, una sociedad libre de cánones de la modernidad y, sobre todo, libre del yugo del poder.

Las pulsiones de los actores sociales se pueden resumir en dos sentimientos: el erotismo y el terror por lo siniestro. En la construcción social y diacrónica del ser humano tales emociones llevadas al extremo se catalogan como sinónimo de fragilidad y retroceso, por eso es necesaria la manipulación y el control de todo síntoma que no esté cobijado bajo la razón y la objetividad. Curiosamente, es otra emoción la que permite fijar un marco rígido de comportamiento social: el miedo. Con la revolución cultural se afianza la exploración del miedo, no como un sentimiento institucionalizado o de control sino como una forma que permite la vivencia de las pulsiones bajo escenarios confortables. El erotismo y lo ominoso son explotados como escapes a la rutina y a la cotidianidad: "liberar al hombre de la tiranía de las prohibiciones y restaurar la actividad del placer" (Benayoun, 1978, p. 8) es la consigna que define los nuevos paradigmas de la oferta y la demanda.

La innovación y el placer son el valor agregado para cualquier mercancía que pretenda convertirse en una tendencia global. El erotismo se diversifica y extrapola a cualquier forma de consumo cultural. Los nuevos estereotipos llevan rasgos salvajes glamurosos de hombres con cabello largo, pecho descubierto y pantalones apretados con un estilo 
despreocupado y sin un afán por el porvenir. Bandas mundialmente reconocidas como Led Zeppelin venden la imagen de Robert Plant como un símbolo sexual para los jóvenes y los movimientos provocadores de Sandro dan rienda suelta a sentimientos antes prohibidos. Agrupaciones musicales como los Rolling Stones y The Beatles imparten una filosofía de revolución sincrética con el afianzamiento de pensamientos orientales. El nuevo esquema de consumo contracultural implementa una reorganización del mundo con el escándalo y la provocación; la minifalda (1965) busca al igual que los grafitis en las calles londinenses y parisinas generar ruido, y logran el objetivo. A principios de los años setenta se produce una ola de turismo en todo el mundo hacia París e Inglaterra, en parte, para observar a los jóvenes rebelándose exhibiendo prendas provocadoras (Miles, 2011).

El erotismo no solo es explotado en la moda y la música. En el año de 1971 llega a las salas de cine la película Garganta profunda (Deep throat), protagonizada por Linda Lovelace. El filme es la primera película pornográfica proyectada en cinemas convencionales y marca un hito en la presentación de imágenes con contenido sexual explícito (Roman, 2005, p. 29). La implosión sexual y su masificación explícita llevan a un clima de sobreproducción de contenidos. La industria del sexo masifica la subcultura leather, mantenido hasta ese momento en secreto, por su perspectiva de una pornografía homosexual con personajes como marineros, vaqueros y demás estereotipos que parodian la masculinidad. La industria que promueve la liberación es también la que somete nuevos estereotipos de fragilidad y sadismo. La mujer continúa siendo vista como una mercancía e incluso ahora es más atractiva explotar de ella todo su contenido sexual, lo cual es ampliamente rechazado por grupos feministas que denuncian la cosificación vulgar de la mujer.

La masificación de los medios de comunicación y el afianzamiento de la tecnología del cine atrapa a los jóvenes en la vivencia continua de realidades fabricadas. Cuando no es el erotismo mercantilizado y la pornografía, es el cine de terror y ciencia ficción con un plus de efec- 
tos especiales que atrapan la atención de las masas. Filmes de terror se vuelven íconos de consumo. Rosemary's Baby relata la vivencia de una joven pareja con un drama particular entre una mujer que desea ser ama de casa y madre y un hombre con anhelos de ser estrella de cine. La conjunción entre lo que es real y lo virtual es imperceptible para Rosemary quien cree haber tenido relaciones con el demonio. El miedo de Rosemary se convierte en paranoia cuando descubre un elaborado plan de sus vecinos para arrebatarle al bebe que es la semilla del diablo. Más allá de la ficción lo que el filme recoge es el miedo de la sociedad, en primer lugar, con asesinatos inexplicables que se daban en diferentes partes con una ritualidad específica; en segundo lugar, la aparente aceptación que están teniendo grupos satanistas en el mundo. Otro fenómeno fílmico que revoluciona y llama la atención de los espectadores es el cine zombi con George Romero como su máximo exponente. Las producciones zombi funcionan como un barómetro a las inquietudes sociales. El temor de la muerte y el peligro de que sean los muertos quienes acaben con el complicado y simbólico mundo de los vivos se convierte en un miedo transcultural. El zombi como concepto es un actor contracultural que está por encima de cualquier poder político, económico y militar. Al zombi no le interesan las formaciones sociales ni el papel que desempeña en la sociedad. Es un organismo vivo, individualizado, sin conflictos comunales y sin afán por el futuro (Fernandez, 2011, p. 19).

La primera etapa de la globalidad se puede definir con una palabra: sincretismo. El préstamo de imágenes virtuales y de la realidad para la construcción de nuevos mitos produce relatos atractivos en latitudes diversas (Barthes, 1980, p. 150). Imágenes como el cura guerrillero Camilo Torres, el Che Guevara, la bandera del socialismo, el Libro rojo de Mao, un monje inmolándose en Vietnam o una niña corriendo quemada por napalm son las nuevas visiones de una realidad que potencializa el consumo -matizado con emociones y perspectivas de revolución-, mientras que en la ficción superhéroes enmascarados resaltan el éxito de la cultura occidentalizada reflejada en el modo de vida norteamericano (Roman, 2002, p. 4). No es coincidencia que imá- 
genes políticamente críticas y socialmente cargadas de un sentimiento revolucionario se produzcan en antiguas periferias, para entonces ya nombradas como países del tercer mundo. Entre tanto, en el primer y segundo mundo la creación de imágenes con alto contenido simbólico se basaen el mundo del espectáculo y del entretenimiento.

Pensadores como Marcuse recogen vivencias de estas periferias como sustento para su teoría social, que es recibida de manera atenta por los jóvenes que se movilizan en el primer mundo llenos de desencanto y angustia. El contexto histórico de países como Alemania a comienzos de los años setenta constituye un invernadero de pasiones nacionalistas, contra-nacionalistas e imperialistas. La visita del Sha de Irán a Alemania motiva pasiones políticas en los jóvenes universitarios (Marcuse, 1968, p. III) mientras las tendencias hegemónicas de un mundo globalizado son denunciadas por esta juventud afanosa por sentir la libertad.La innovación imperialista se fundamenta no en un dominio militar ni en un control social institucionalizado sino con la venta de nuevas tecnologías que lleva a países emergentes a depender de estas o a anhelar su uso. Marcuse define los tiempos contemporáneos como tiempos de la utopía; la utopía es una categoría histórica que busca la transformación social sin importar si logra alcanzarse o no (Marcuse, 1968, p. IV). Lo fundamental del estudio marcusiano es la radiografía de la sociedad y, siendo más específicos, de los actores sociales que están influyendo de manera directa y espontánea en la misma, o sea, los jóvenes de los sesenta, la primera generación de la utopía.

Desde 1968, punto de inicio del capitalismo posindustrial, la juventud se hace visible como nunca antes bajo la consigna no solo de crear nuevas formas de interpretación de la sociedad sino de actuar ante sus problemas. Esta generación de jóvenes es un grupo poblacional contracultural por naturaleza, no importa si es de la realidad capitalista de Los Ángeles, del sincretismo parisino de la protesta, del bloque comunista que demanda libertades o de una realidad latinoamericana dispar. Todos buscan un cambio y, lo más importante, tienen la posibilidad de contrastar su realidad con la de otros contemporáneos. Entre 
las realidades también existen puntos en común: todos crecen con los relatos de miedo, guerra y muerte de sus padres y abuelos. Sin una gran depresión o una gran guerra respiran un hastío tecnócrata-existencialista mientras consumen tanta información como ninguna otra generación anterior a ellos. Son omnívoros culturales (Peterson, 2005, p. 257-282) o consumidores que disponen de un abanico de gustos relativamente amplio; es la primera generación en tener una percepción de ser uno en el mundo y compartir utopías, emociones y sentimientos de la totalidad del planeta (globalidad).

\section{A manera de conclusión}

El capitalismo en su amplia historia de casi cinco siglos hace creer que la crisis es sinónimo de dinamismo, que la aporía es el motor del cambio y que la única forma de sobreponerse es produciendo, consumiendo e innovando (Berman, 1988, p. 98). El capitalismo globalizado en su más reciente etapa ha desarrollado un avance tecnológico a gran escala permeando a lo social y definiéndolo bajo los mismos estándares de producción. La sociedad de la posguerra se caracteriza por su afán de materializar un ideal y comercializarlo: la libertad. La mecanización y tecnocratización de las experiencias sociales lleva a desplazar pulsiones y sentimientos en lo que se cree es un proceso imparable de la innovación y la sociedad posindustrial.

El problema de esta investigación es ċsi la innovación tecnológica y la mutabilidad en las estructuras sociales convierten a los actores sociales y su percepción de sí-mismos en arcaísmos, sería necesaria una continua re-definición de las categorías sociales que llevara a una reinvención de versiones mejoradas de sí mismos? La innovación es un éxito rotundo que convierte la noción de juventud, cuyo objetivo en la década de los sesenta es la utopía, la libertad y el placer, a una noción categorizada por la instantaneidad, el exceso de información y la necesidad prematura del reconocimiento en el siglo XXI (Gleick, 2012, p. 215). En ambas concepciones existe un factor fundamental que describe la tendencia de consumo y movilización que es la libertad y la rebelión como mecanismo para conseguirla; al final no son más que 
un valor agregado del sistema para la creación y posicionamiento de nuevas mercancías y necesidades por vender.

Las generaciones emergentes creen y hacen todo lo necesario por generar una dinámica que parta de la independencia, los defina y haga sentir únicos, como una pieza clave en el mundo globalizado, pero terminan inmersos y son adormecidos con el confort y el placer de consumir mientras creen que están definiendo su autonomía para terminar como autómatas ${ }^{4}$. La ficción de la independencia y el ideal de libertad lleva a buscar en la innovación la libertad, pero se está es condicionando la voluntad a poderosos emporios de los medios de comunicación y la tecnología, los cuales hacen creer que se están generando nuevas formas de rebelión cuando en verdad lo que se está haciendo es ampliar el espectro de consumo. 


\section{Referencias}

Acevedo , A., \& Restrepo, R. (2009). Una lanza de libertad por un proyecto de nación inconcluso: Nadaismo en Colombia. Historia de la educación latinoamericana, (12), 62-78. Recuperado de http://www.redalyc.org/articulo. oa?id=86912021004

Acevedo , Á., y Restrepo, R. (2012). Nadaismo y Revolucion Cultural 1958-1972. Politecnica, 8(14), 141-148. Recuperado de: http://www2.politecnicojic.edu.co/ images/stories/medios/revista politecnica/revista 14.pdf

Acevedo Tarazona, Á. (2016). La experiencia histórica del cogobierno en la Universidad Industrial de Santander. Bucaramanga: División de publicaciones UIS.

Archive.org. (junio de 2008). archive.org. Obtenido de Wayback machine.Recuperado de: http://web.archive.org/web/20080613120100/http://www.camus.edu. $\underline{\mathrm{mx} / 20 / \text { primera guerra mundial.htm }}$

Aristóteles. (1990). Retórica. Madrid: Gredos.

Baudelaire, C. (2009). Las flores del mal. Madrid :Edaf.

Baker, C. (1996). British army statistics if the Great War. Recuperado: junio de 2013, disponible enwww.1914-1918.net/faq.html

Barraclough, G. (1964). Introducción a la historia contemporanea. Madrid: Gredos.

Barthes, R. (1980). Mitologías. Mexico DF: Siglo XXI.

Baudrillard, J. (2007). Lo virtual y lo acontecedero. Archipielagos, (79), 85-101. Recuperado de: http://www.archipielago-ed.com/79/index.html

Bauman, Z. (2013). La cultura en el mundo de la modernidad liquida. Madrid: FCE. BBC Economy. Richest 1\% to own more than the rest of world (19 de enero de 2012).

Recuperado el 5 de julio de 2015, de: http://www.bbc.com/news/busi$\underline{\text { ness }-30875633}$

Camus, A. (1953). El hombre rebelde . Buenos Aires : Losada.

Beck, U. (2008). ¿Qué es la globalizacion? falacias del globalismo. Barcelona: Paidós. 
Benayoun, R. (1978). Érotique du surréalisme. París: Éditions Pauvert.

Berman, M. (1988). Todo lo sólido se desvanece en el aire. Madrid: Siglo XXI Editores.

Bourdieu, P. (2002). La juventud no es más que una palabra. México D.F.: Grijalbo.

Camus, A. (1953). El hombre rebelde. Buenos Aires: Losada

Carassai, S. (2013). Los años setenta de la gente común. Buenos Aires: Siglo XXI.

Chartoff, R. (Productor) y Avildsen, J. (Director). (1976). Rocky. [Cinta cinematográfica]. Estados Unidos.

Deleuze, G. (2002). Diferencia y repetición. Buenos Aires: Amorrortu.

Diccionario Vox. (1967). Diccionario VOX- Griego Clasico - Español. (J. Pabon, Ed.) Madrid.

Diccionario Vox. (2011). Diccionario Vox Latin- Español.Madrid: vox.

Dubuffet, J. (1986). Asphyxiating culture and other writings. New York: Four Walls Eight Windows.

Fazio, H. (2011). ¿Qué es la globalización? Bogotá: Uniandes.

Fernandez, J. (2011). Filosofía zombi. Barcelona: Anagrama.

Gleick, J. (2012). Información. Barcelona: Critica.

Guerrero, M.T. (2008). Colombia a traves del ojo del artista. Bogotá: Universidad de los Andes.

Habermas, J. (1989). El discurso filosófico de la modernidad. Madrid: Taurus.

Hobsbawm, E. (1997). Historia del siglo XX. Barcelona: Crítica.

Kotcheff, T. (Director). (1982). Rambo. [Cinta cinematográfica]. Estados Unidos.

Kundera, M. (1967). La broma . Barcelona: Tusquets.

Levin, I. (Escritor) \& Polanski, R. (Director). (1968). Rosemary's baby. [Cinta cinematográfica]. Estados Unidos: Paramount Pictures.

Lipovetsky, G., \& Serroy, J. (2015). La estetizacion del mundo . Barcelona: Anagrama Marcuse, H. (1968). El final de la utopia. Barcelona: Planeta.

Marcuse, H. (1973). Contrarrevolución y revuelta. Mexico: Joaquin Mortiz. 
McLuhan, M. (1965). Undestanding Media: The extensions of a man. New York: Mc Graw- Hill.

McLuhan, M. (1969). Contraxplosión. Buenos Aires: Paidos.

Miles, B. (30 de Enero de 2011). Spirit of the underground: the 6os rebel. The Guardian. Recuperado de: https://www.theguardian.com/culture/2011/jan/30/ underground-arts-60s-rebel-counterculture

Muñoz, B. (2005). Cultura Global, Medios de comunicación, cultura e ideologia en la sociedad globalizada. Madrid: Pearson.

Ulrich, B. (2002). La cultura globalizada. Madrid: Siglo XXI.

Peraino, L. (Productor) y Damiano, G. (Director). (1972). Deep throat. [Cinta cinematográfica]. Estados Unidos.

Peterson, R. (2005). Problems in comparative research: the example of omnivorousness. Poetics, 33(5), 257-282. Recuperado de: http://www3.nd.edu/ sskiles/ soco\%20articles/Peterson\%202005.pdf

Ramirez, L. (2003). El gobierno de Rojas y la inaguración de la televisión: Imagen Política, educación popular y divulgación cultural. Historia Critica, (22), 131156. Recuperado de: https://historiacritica.uniandes.edu.co/view.php/403/ index.php?id=403

Restrepo, J. (2002). La generación rota. Contracultura y revolución de posguerra. Bogotá: Planeta.

Robertson, R. (1992). Globalization: theory social and global culture. New York: Sage Publications.

Roman, G. (2002). Máscaras de la ficción. Barcelona: Anagrama.

Roman, G. (2005). La imagen pornográfica y otras perversiones ópticas. Barcelona: Anagrama.

Romero, G. (Director). (1968). The night of the living dead.[Cinta cinematográfica]. Estados Unidos.

Wallerstein, I. (2003). Nuevas revueltas contra el sistema. Movimientos, 93- 
103. Recuperado de: http://newleftreview.es/article/download pdf?language $=e s \& i d=226$

Waters, M. (1995). Globalization. Londres: Routledge.

Zizek, S. (2014). Acontecimiento . Mexico DF: Sexto piso 